\title{
The Role of Reflection in Facilitating and Assessing Innovativeness
}

\author{
Juhani Ukko', Minna Saunila²
}

\begin{abstract}
The aim of the research is to study the features that should be taken into account when facilitating innovations through reflection, and focusing on the impacts of reflection on innovation. A single case study approach was used in the study. The data was gathered with semi-structured interviews and also innovation measurement data were gathered from the company. To achieve an overall view of the studied organization with regard to the research questions, representatives from different organizational levels were interviewed. In total, six interviews were conducted, including the director, two managers and three employees. The studies of different innovation measurement and management have mainly been theoretical considerations. Further, the role of reflection in facilitating innovation in organizations has been neglected in current literature. The current study presents the features of reflective procedure of facilitating and assessing innovations. The results can be utilized by managers working with innovation management.
\end{abstract}

Keywords: innovation; reflection; facilitation; assessment; measurement; performance; impacts

\footnotetext{
1,2 Lappeenranta University of Technology, Lahti School of Innovation, Saimaankatu II, I5I40 Lahti, Finland.

'E-mail: juhani.ukko@lut.fi.
} 


\section{Introduction}

The importance of the development of an organization's innovation capability for its success is highlighted in current literature. The ability to innovate is generally accepted as a critical success factor for the growth and future performance of firms, and it is also seen as the only means by which companies can sustain competitive advantage (Carayannis and Provance, 2008; Muller, Välikangas and Merlyn, 2005). Attention should be paid not only to adequate resources invested in R\&D, but also to innovation capabilities (Forsman and Rantanen, 20I I). The link between strategy and innovation activities, together with a shared vision of innovation, is essential when creating innovation capability (e.g. Davila, Epstein and Shelton, 2006; Lawson and Samson, 200I; Skarzynski and Gibson, 2008). Organizational structure and systems are essential in encouraging organizations towards innovativeness. A decentralized and informal structure of the organization, as well as a flexible structure of innovation, are seen to support new idea generation (Dobni, 2008; Leach, Stride and Wood, 2006; Subramanian and Nilakanta 1996). Bringing innovation to every workstation requires practical tools, processes, and mechanisms, which the employees can use day by day (Skarzynski and Gibson, 2008).

One of the key antecedents to innovativeness is learning orientation meaning that when members of an organization acquire knowledge via the learning process the organization acquires the ability to be innovative (e.g., Hult, Hurley and Knight, 2004). Learning always requires reflection. The relationship between reflection and innovativeness has not been studied, not at least in organizational level. However, there are similarities as regards the antecedents and nature of the concepts as well as previous research on team reflection which creates a premise of the connection between these two phenomena.

This paper presents a single case study, where a reflective procedure of facilitating and assessing innovations was implemented in an organization. The case company is a store operating in the fields of construction, decoration and gardening, employing around 50 persons. The store has been established in 2007 , having thus a lot of potential for creating innovations across organization.

We have grounded our research on the essential features that should be taken into account when facilitating and assessing innovations through reflection. Hence, the following research questions will be addressed in this paper:

I. How to facilitate innovativeness through reflection?

2. What impacts does the reflection have on innovation activities aiming to enhance organizational performance?
The study consists of six chapters including the introduction, a literature review, the research approach, results, discussion and conclusions. The literature review covers the organizational innovativeness and innovation structures, the important features for assessing ideation, and the role of reflection in innovation capability. The research approach includes the criteria for the single case study, for the case selection, and for the data collection and analysis. In the result chapter, the findings related to the posed research questions are presented. The last two chapters consist of a discussion and conclusions of the results and summarize the contribution of the study.

\section{Literature review}

\section{Organizational innovativeness and innovation structures}

Innovation can be seen as a process of turning opportunity into new ideas and of putting these ideas into widely used practice (Tidd, Bessant and Pavitt, 2005). There are two key aspects of innovation: the degree of innovation and the scope of innovation. The degree of innovation is divided into radical and incremental innovation. The scope of innovation capability consists of technical innovation and administrative innovation (Lin, Chen and Chiu, 2010). The successful operation of organizations in almost all industries is becoming highly dependent on their ability to produce innovations. Muller, Välikangas and Merlyn (2005) present that today, more than ever, companies must exploit their innovative capabilities to develop new businesses if they are to successfully confront the disruptive effects of emerging technologies, empowered customers, new market entrants, shorter product life cycles, geopolitical instability, and market globalization. Muller, Välikangas and Merlyn (ibid.) continue that the development of innovative capabilities is the only means by which companies can sustain a competitive advantage. It is essential to focus on how innovation capability can be refined to innovations in the most effective way.

Lawson and Samson (200I) state that the elements making up an innovation capability are vision and strategy, harnessing the competence base, organizational intelligence, creativity and idea management, organizational structure and systems, culture and climate, and management of technology. Skarzynski and Gibson (2008) highlight the sharing of a common vision of innovation among the leaders and organization, a disciplined approach to building innovation capabilities across the organization, supporting tools to enable an idea generation pipeline and portfolio management, and a collaborative, open culture and incentives that reward challenging current actions. 
The innovation structure is in a key role as regards a shared vision of innovation and idea generation across the organization. There is a common agreement on the necessity of flexible structures for innovation (Dobni, 2008; Nahapiet and Ghoshal, 1998; Subramanian and Nilakanta, 1996). According to Subramanian and Nilakanta (1996), decentralized and informal organizational structures facilitate innovations. They also propose that the flexibility and openness of structures helps to encourage new idea generation. In a dynamic environment, the organizational structure will need to be more open than precisely defined, more emotionally-inclusive than rationally-inclusive, more interactive than integrative, more temporal, more flexible, and trustand informality-based (Wang and Ahmed, 2003). Bringing innovation to every workstation requires practical tools, processes, and mechanisms, which the employees can use day by day to turn innovation into the organization's capability (Skarzynski and Gibson, 2008).

\section{Features important for the assessment of innova- tiveness}

The assessment process of ideas and innovations is an essential element to keep up employees' motivation. Important questions concerning the assessment of ideas are for example how often the ideas should be evaluated, who should participate in the decision making, how the decisions should be made, and how to link the ideas to organizational goals. One reason for failure in motivating employees is long delays in getting the ideas processed (e.g. Fairbank, Spangler and Williams, 2003). In the performance management literature, for example Bourne, Kennerley and Franco-Santos (2005) state that in high-performing units, the managers' use of performance measurement is interactive, and they intensively communicate and discuss performance both at formal meetings and "at every opportunity".

Performance management literature also presents that the employees' possibility to participate in decision making should be highlighted, especially when the measurement concerns an individual's own job and targets Johnston, Brignall and Fitzgerald, 2002; Kaplan and Norton, 1996; Lingle and Schiemann, 1996; Simons, 2000; Ukko, Tenhunen and Rantanen 2008). A transparent process for evaluating ideas, timely feedback regarding the fate of ideas and rewards, together with the idea's presenters' possibility to query and interact with others should be taken into account in the evaluation process (Fairbank and Williams, 200I; Fairbank, Spangler and Williams, 2003). Generally, the presenters should understand the process through which their ideas are evaluated (Fairbank and Williams, 200I). Further, the assessment and measurement of ideas should also be related to the innovation strategy and organizational goals (Davila, Epstein and Shelton, 2006; Fairbank and Wil- liams, 200I). For example, Fairbank and Williams (200I) present that approaches that are structured in the manner described above also align employees' goals with their organizations' priorities.

\section{The role of reflection in innovativeness}

Reflection can be considered key issue when promoting innovativeness. Organizational renewal and innovation is as much about making sense as about the situation, that is, learning new ways of thinking and acting (Hildén, Tikkamäki and Suomala, 2012). Reflection involves thinking about past or ongoing events, situations or actions so as to make sense of them, potentially with a view to informing future choices, decisions or actions (Reynolds, 20I I). Boud defines reflection as "a generic term for those intellectual and affective activities in which individuals engage to explore their experiences in order to lead to a new understanding and appreciation". (in Mann, Gordon and MacLeod, 2009) Reflection thus fulfills several functions, including helping to make sense of complex situations and enabling learning from earlier experience (Mann, Gordon and MacLeod, 2009).

Reflection can also occur collectively and that dialogue is a critical component in reflective practices as a part of learning processes (Nakamura and Yorks, 20II). The ability to reflect seems to be amenable to development over time and with practice and in the presence of group work. Discussing challenging situations or problems with supervisors, mentors, colleagues and other with greater experience seems to be important for reflection. (Mann, Gordon and MacLeod, 2009; Nakamura and Yorks, 20I I) Actually, support for planning and reflection is essential. This can come true through freedom and possibility to reflect, to make plans, to keep meetings and to get feedback on actions and plans. (Høyrup, 2004)

As presented earlier, there are many similar factors behind reflection and innovativeness. These include for example including individual skills and capabilities, collective culture and structural aspects. There are some examples in the current literature suggesting that team reflection is driver of both team innovation (Somech, 2006) and product innovation (Lee, 2008). According to Somech (2006), the process of team reflection serves as a vehicle through which the interaction of participative leadership style and functional heterogeneity enhances team innovation. Also reflective project leadership, meaning questioning one's own leader behavior, can be a way for project leader to promote innovativeness (Ollila, 2000). 


\section{Method}

This study is a single case study. The studies of the facilitation and assessment of innovativeness have mainly been theoretical considerations or surveys that lack in-depth understanding of how the different mechanisms and features operate in a real life context. According to Yin (2003), one rationale for using a single case study is the researcher's access to a situation previously inaccessible, and therefore the descriptive information alone will be revelatory. This has been a guideline for the research strategy of this study.

The case company is a store operating in the fields of construction, decoration and gardening, employing around 50 persons. A reflective procedure of facilitating and assessing innovations was designed and implemented in the organization during one year development project. The store has been established in 2007, having thus a lot of potential for creating innovations across organization. The store also manages very well in financial measures compared to its competitors. The researchers were involved in the design process of reflective procedure, which increased their preunderstanding of the case context.

The reflective procedure was created in the case company through one and a half year action oriented development project. Cooperation with the case company started in autumn 2009. The existing practices of the organizations were explored by conducting a diagnosis. The main purpose was to form an understanding of the innovation process and the state of innovation capability in case company. The diagnosis phase included interviews among the employees (both operational and management), stakeholders and customers of the case company, collecting narratives and conducting an Internet survey. To achieve an overall view of the needs of the organization, employees from all organizational levels participated in the diagnosis.After the diagnosis, a team of employees representing different departments of the case company was chosen to develop the innovation and ideation process with the support of the researchers. The criterion for selection of the participants was that they should have an active role in the organization. Researchers had an important role in workshops. Before the workshops they analyzed the results of diagnosis and made suggestions for topics of workshops for the management of case organization. Researchers then defined the issues and questions for the workshops. As a result of the workshops, the reflective procedure of generating, developing and assessing ideas was identified in collaborative workshops lead by researchers. The reflective procedure included electronic software for facilitating the idea generation and weekly meetings where the ideas are assessed and developed further through reflective dialogue.

The follow-up data was gathered with semi-structured interviews about one year after the development project ended. Also innovation measurement data were gathered
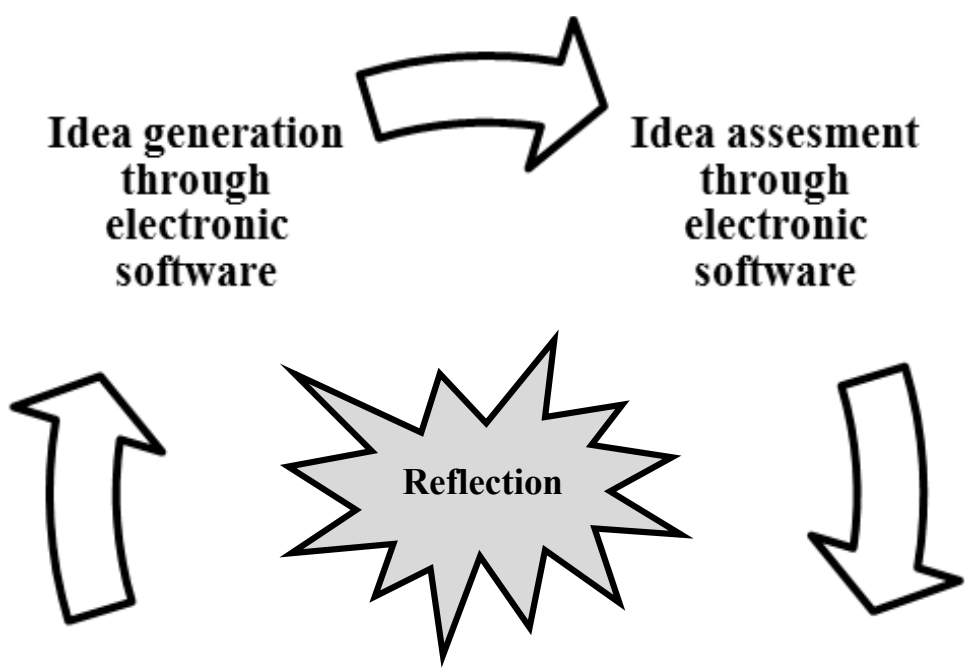
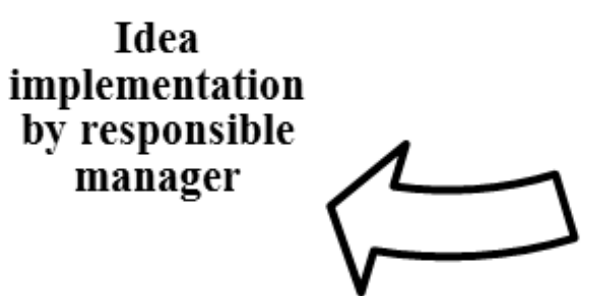

Figure I. Reflective procedure for facilitating and assessing innovations.

ISSN: 07 I8-2724. (http://www.jotmi.org) 
from the company. The semi-structured interviews included core questions, allowing additional questions when needed. This enabled in-depth understanding of the phenomenon under investigation. To achieve an overall view of the studied organization with regard to the research questions, representatives from different organizational levels were interviewed. In total, six interviews were conducted, including the director, two managers and three employees. Content analysis was carried out in the studied issues, with the intention to clarify how the innovations were facilitated through reflection and what impacts the reflection has had on the innovation activities aiming to enhance organizational performance. The extent and emphasis of the statements of the interviewees were highlighted in the analysis.

\section{Results}

\section{Facilitating innovativeness through reflection}

It was considered that after launching the reflective procedure, all the employees had now equal possibilities to introduce their own ideas, as well as to comment on the ideas produced by other employees. This was caused by the form of the system, allowing support, comments and additional questions on all generated ideas, and the transparent presentation of all the ideas and comments regardless of the status of the idea. Earlier, the ideas where mainly discussed with the supervisor, which limited the participation of the shy and new employees. The ignoring of ideas was also easier with that type of informal procedure. The discussion with the supervisor and the utilization of a manual procedure were also considered as time-consuming, without a real possibility for the transparency that is needed for the fairness of the procedure.

The interviewees common opinion was that their organizational culture encourages presenting all kinds of ideas without the need for anonymous methods. They also stated that presenting an idea with one's own name eases the reflective evaluation process, when the presentation of additional questions and individual feedback is possible. Further, the interviewees said that their system allowed the anonymous presenting of ideas, but this feature was used hardly at all.

According the interviewees, the communication and feedback were presented mainly through the electronic software. This was considered as the best way in most cases, as the system was considered transparent, interactive and time-saving, including well defined stages for the idea processing. However, the interviewees thought that the accepted innovations could also be presented to the employee groups they were intended to impact on (e.g. in department or company meetings). This kind of publicity was seen as rewarding feedback that would encourage also other em- ployees to generate ideas. The company offered a small and fixed reward for the accepted ideas. Only the accepted ideas were recognized with this reward. Some of the interviewees considered that ideation is everyone's task, and publicity and non-monetary rewards are the most effective ways to facilitate idea generation. Others saw that without proportional rewards, the best ideas, involving a lot of brainwork, would not be presented, and the activity of using the system would be reduced. The valuation of an idea (e.g. growth in sales) was considered difficult by the interviewees, which also hindered the use of proportional rewards.

\section{Impacts of reflection on innovation activities}

Reflective dialogue took place mostly in the evaluation meetings. In the weekly evaluation meetings, one manager and one employee from each department were involved, and the experienced service manager operated as the administrator of the meetings. The employee participants were changed for every meeting. This type of participatory evaluation was considered as a workable method for various reasons.

Participating in the reflective procedure of enhancing innovativeness increases the employees' understanding of the idea evaluation process, allows the presentation of how the ideas influence the employees' tasks, and enhances crossfunctional communication and the sense of fairness. In the reflective evaluation meetings, the new and reviewed ideas were presented by a different manager in each meeting. Support for the ideas was discussed on the basis of the support they had received and comments that had been gathered from the system. The decision making was considered to be consensus-seeking and democratic. The interviewees perceived this as essential, because most of the ideas would concern an individual's own job. It was also considered easier for the presenters to accept rejection of their ideas, when a peer review had been made by a number of colleagues instead of one responsible manager. In the reflective evaluation meetings, some effort was made to align the ideas with the organizational goals (e.g. sales growth, sales/ working hours, customer satisfaction, average shopping). The interviewees considered this an important issue by stating that all the changes in the organization should serve the organizational goals. However, this evaluation was done with very subjective methods, and more formal and sophisticated methods were needed.

Measures, assessing the process of generating ideas, were calculated weekly in the evaluation meeting and reported on a monthly basis. Since the active use of the system was considered essential, the number of presented and implemented ideas, together with the support received by the idea were seen as best indicators for the activity. The outcome measures were considered important, but they were 
still under construction. All the interviewees stated that the employees were interested only in the implemented ideas and changes in the organization. Thus, the measurement was mainly utilized by the managers who were responsible for the development and active use of the system.

The impact of the measurements, when reflected together in monthly meetings, on innovation activities was realized mainly through the number of the implemented ideas. The implemented ideas that were originally presented by a certain department, were perceived to facilitate the generation of ideas in other departments. Further, the employees were seen to perceive their work as more important through the participation and especially through the implemented ideas.

\section{Discussion}

The study presented a single case study, where the mechanisms of facilitation and assessment of innovations through a reflective procedure were examined in a real life context. According to Somech (2006), the process of team reflection serves as a vehicle through which the interaction of participative leadership style and functional heterogeneity enhances team innovation. The results of the current study support this view by concluding that reflection plays an important role in facilitating innovativeness across organization.

First, the transparency of the procedure of generating innovations motivates reflection and further generating ideas. It encourages all members of the organization to participate in the ideation. As Nakamura and Yorks (20II) state, reflection can also occur collectively and that dialogue is a critical component in reflection as a part of learning processes. Participating in the reflective procedure of enhancing innovativeness increases the employees' understanding of the idea evaluation process, allows the presentation of how the ideas influence the employees' tasks, and enhances cross-functional communication and the sense of fairness. Further, the assessment and measurement of ideas should also be related to the innovation strategy and organizational goals (Davila, Epstein and Shelton, 2006). The importance of reflecting the measurement results was amplified in this study, because it increases the activity of innovating.

The empirical evidence was based on a reflective procedure created during an action oriented development project, follow-up interviews and measurement data in one company, which limits the generalizability of the findings. Although the results supported many of the propositions in prior literature, they also generated a number of open questions for further research. First, more sophisticated methods are needed for the valuation of the idea, enabling better utilization of proportional rewards and the alignment of the ideas with organizational goals. Second, it is worth examining more detailed in what types of impacts does it result when utilizing reflective procedures in innovation management. Third, it seems that innovation measurement depends on many factors, and it is thus important to study how innovation measurement should be organized in different business areas and with different types of reflective innovation processes.

\section{References}

BOURNE, M., Kennerley, M., Franco-Santos, M. (2005). Managing trough measures: $A$ study of impact on performance. Journal of Manufacturing Technology Management, 16(4), 373-395.

CARAYANNIS, E.G., Provance, M. (2008). Measuring firm innovativeness:Towards a composite innovation index built on firm innovative posture, propensity and performance attributes. International Journal of Innovation and Regional Development, I (I), 90-I07.

DAVILA, T., Epstein, M.J., Shelton, R. (2006). Making Innovation Work: How to Manage It, Measure It, and Profit from It, Wharton School Publishing, Upper Saddle River, NJ.

DOBNI, C.B. (2008). Measuring innovation culture in organizations:The development of a generalized innovation culture construct using exploratory factor analysis. European Journal of Innovation Management, I I (4), 539-559.

FAIRBANK, J.F., Spangler,W.E.,Williams, S.D. (2003). Motivating creativity through a computer-mediated employee suggestion management system. Behaviour \& Information Technology, 22(5), 305-3I4.

FAIRBANK, J.F., Williams, S.D. (200I). Motivating creativity and enhancing innovation through employee suggestion system technology. Creativity and Innovation Management, I0(2), 68-74.

FORSMAN, H., Rantanen, H. (20I I). Small manufacturing and service enterprises as innovators: a comparison by size. European Journal of Innovation Management, I4(I), 27-50.

HILDÉN, S., Tikkamäki, K., Suomala, P. (2012). Reflection for renewal. OCD - Organizational Change and Development Conference, September 13-I4, 2012, Switzerland.

HØYRUP, S. (2004). Reflection as a core process in organisational learning, Journal of Workplace Learning, 16(8), 442454. 
HULT, G.T.M., Hurley, R.F., Knight, G.A. (2004). Innovativeness: Its antecedents and impact on business performance, Industrial Marketing Management, 33(5), 429-438.

JOHNSTON, R., Brignall, S., Fitzgerald, L. (2002). 'Good enough' performance measurement: $A$ trade-off between activity and action. Journal of the Operational Research Society, 53(3), 256-262.

KAPLAN, R.S., Norton, D.P. (1996). The Balanced Scorecard. Translating Strategy into Action, Harvard Business School Press, Boston.

LAWSON, B., Samson, D. (200I). Developing innovation capability in organisations: A dynamic capabilities approach. International Journal of Innovation Management, 5(3), 377-400.

LEACH, J., Stride, C.B., Wood, S.J. (2006). The effectiveness of idea capture schemes. International Journal of Innovation Management, I0(3), 325-350.

LEE, L.T-S. (2008). The effects of team reflexivity and innovativeness on new product development performance, Industrial Management \& Data Systems, 108(4), 548-569.

LIN, R-J., Chen, R-H., Chiu, K.K-S. (20I0). Customer relationship management and innovation capability:An empirical study. Industrial Management \& Data Systems, I IO(I), III133.

LINGLE, J.H., Schiemann, W.A. (1996). From balanced scorecard to strategic gauges: Is measurement worth it?. Management Review, 85(3), 56-62.

MANN, K., Gordon, J., MacLeod, A. (2009). Reflection and reflective practice in health professions education: a systematic review. Advances in Health Sciences Education, 14(4), 595-621.

MULLER, A., Välikangas, L., Merlyn, P. (2005). Metrics for innovation: Guidelines for developing a customized suite of innovation metrics. Strategy \& Leadership, 33(I), 37-45.

NAHAPIET, J., Ghoshal, S. (1998). Social capital, intellectual capital and the organizational advantage. Academy of Management Review, 23(2), 242-266.

NAKAMURA, Y.T., Yorks, L. (20I I). The Role of Reflective Practices in Building Social Capital in Organizations From an HRD Perspective, Human Resource Development Review, I0(3), 222-245.
OLLILA, S. (2000). Creativity and Innovativeness through Reflective Project Leadership, Creativity and Innovation Management, 9(3), 195-200.

REYNOLDS, M. (20II). Reflective practice: origins and interpretations, Action Learning: Research and Practice, 8(I), 5-13.

SIMONS, R. (2000). Performance Measurement \& Control Systems for Implementing Strategy, Prentice Hall, New Jersey.

SKARZYNSKI, P., Gibson, R. (2008). Innovation to the Core: A Blueprint for Transforming the Way Your Company Innovates, Harvard Business School Press, Boston.

SOMECH, A. (2006). The Effects of Leadership Style and Team Process on Performance and Innovation in Functionally Heterogeneous Teams, Journal of Management, (32)I, I32-I57.

SUBRAMANIAN, A., Nilakanta, S. (1996). Organizational innovativeness: Exploring the relationship between organizational determinants of innovation, types of innovations, and measures of organizational performance. International Journal of Management Science, 24(6), 63 I-647.

TIDD, J., Bessant, J., Pavitt, K. (2005). Managing Innovation: Integrating Technological, Market and Organizational Change, John Wiley \& Sons, West Sussex.

UKKO, J., Tenhunen, J., Rantanen, H. (2008). The impacts of performance measurement on the quality of working life. International Journal of Business Performance Management, I0(I), 86-98.

WANG, C.L., Ahmed, P.K. (2003). Structure and structural dimensions for knowledge-based organizations. Measuring Business Excellence, 7(I), 5I-62.

YIN, R. (2003). Case Study Research: Design and Methods, 3rd edition, Applied Social Research Methods Series, Vol. 5, Sage Publications, Thousand Oaks, California. 